\title{
The Impact of Active Learning in a Speech-Language Pathology Swallowing and Dysphagia Course
}

\author{
Rebecca H. Affoo \\ Central Michigan University, rebecca.affoo@dal.ca \\ Justin L. Bruner \\ Michigan State University, jbruner@msu.edu \\ Angela M. Dietsch \\ University of Nebraska-Lincoln, angela.dietsch@unl.edu
}

See next page for additional authors

DOI: https://doi.org/10.30707/TLCSD4.2/POPG6689

Follow this and additional works at: https://ir.library.illinoisstate.edu/tlcsd

Part of the Speech Pathology and Audiology Commons

\section{Recommended Citation}

Affoo, Rebecca H.; Bruner, Justin L.; Dietsch, Angela M.; Nellenbach, Ciara E.; Jones, Theresa M.; and Lehman, Mark E. (2020) "The Impact of Active Learning in a Speech-Language Pathology Swallowing and Dysphagia Course," Teaching and Learning in Communication Sciences \& Disorders: Vol. 4: Iss. 2, Article 4.

DOI: https://doi.org/10.30707/TLCSD4.2/POPG6689

Available at: https://ir.library.illinoisstate.edu/tlcsd/vol4/iss2/4

This Scholarship of Teaching and Learning Research is brought to you for free and open access by ISU ReD: Research and eData. It has been accepted for inclusion in Teaching and Learning in Communication Sciences \& Disorders by an authorized editor of ISU ReD: Research and eData. For more information, please contact ISUReD@ilstu.edu. 


\title{
The Impact of Active Learning in a Speech-Language Pathology Swallowing and Dysphagia Course
}

\author{
Abstract \\ The signature pedagogy in Speech-Language Pathology (SLP) higher education programs has been \\ criticized for its instructor-centric lecture format and emphasis on the lower tiers of Bloom's taxonomy \\ (simply memorizing knowledge) at the expense of helping students develop the clinical problem-solving \\ skills required for a lifetime of practice and learning. The purpose of this study was to examine the \\ responses of a cohort of graduate speech-language pathology students to an active learning-oriented \\ swallowing and dysphagia course design. A potential relationship between student perceptions of the \\ active learning pedagogy and academic performance was also explored. The results suggest that active \\ learning positively impacted both student perceptions and performance in the redesigned swallowing and \\ dysphagia course.
}

\section{Keywords}

active learning, dysphagia, speech-language pathology, evidence based education, team based learning, swallowing

\section{Cover Page Footnote}

The authors would like to acknowledge the contributions of the SLP students at Central Michigan University and the SLPs in our community who provide invaluable clinical supervision and teaching.

\section{Authors}

Rebecca H. Affoo, Justin L. Bruner, Angela M. Dietsch, Ciara E. Nellenbach, Theresa M. Jones, and Mark E. Lehman 


\section{Introduction}

Swallowing disorders are a high-stakes area of practice for speech-language pathologists (SLP), since misdiagnosis can lead to mismanagement of limited healthcare resources, reduced quality of life for patients, and even increased mortality. Thus, education and training in this realm are critical, and the implications of a potential gap in that preparation are dire. Mastering even the core competencies of swallowing and dysphagia however presents a unique challenge for students and educators in Communication Sciences and Disorders (CSD). The breadth, depth, and complexity of the relevant foundational knowledge are extensive, and have relatively little overlap with other topics in CSD. The requisite knowledge and skills for dysphagia practitioners have been expanded beyond swallowing to include feeding, orofacial myology, pulmonary, and gastrointestinal systems (American Speech-Language-Hearing Association [ASHA], n.d.-a). Further, university faculty are often pressed to cover all the required content and related professional skills in a restrictive single-semester timeframe (Ball \& Riquelme, 2016) and with limited instructional guidance or support (Ginsberg, 2010).

To achieve clinical competency in the area of swallowing and dysphagia, students must master this foundational knowledge and also be able to apply and analyze it in a range of contexts. Currently, the signature pedagogy in CSD utilizes a theory-first model wherein students are taught the foundational knowledge before they are involved in clinical activities (Brackenbury et al., 2014). These foundations are commonly taught in the traditional lecture-based format, focusing on recall and repetition, and often build on information taught in earlier courses. Brackenbury et al. (2014) highlighted a potential weakness of this structure in that it may not foster students' independence in learning to connect information between the various components of foundational knowledge and their clinical application in different contexts. Providing students with opportunities to practice application and analysis of their swallowing and dysphagia foundational knowledge in different simulated clinical contexts while still in the classroom could be one way to remedy this potential weakness.

Alternative teaching strategies designed to increase student engagement could help to resolve the challenges related to education and training and better prepare graduate CSD students for clinical practice in swallowing and dysphagia. Active learning pedagogy provides students with opportunities to practice application and analysis of foundational knowledge in different contexts in addition to facilitating development of professional skills related to teamwork, independent learning, problem-solving, critical thinking, and communicating. Active learning is defined as "any instructional method that engages students in the learning process" (Bonwell \& Eison, 1991, p. 2). There are many active learning techniques that can be implemented by educators and numerous studies have reported the benefits of using active learning techniques compared with traditional lectures. The benefits include decreased failure rates (Freeman et al., 2014), improved performance on tests (Deslauriers et al., 2011; Hake, 1998), improved short- and long-term retention (Di Vesta \& Smith, 1979; Ruhl et al, 1987), and improved understanding of concepts (Laws et al., 1999; Redish et al., 1997). Strategies like this, applied in CSD graduate training, seem well-suited to help prepare students for the next steps of their training-supervised practice of their swallowing-related knowledge and skills in real-life clinical externship situations. 
Edgar Dale's "Cone of Experience" (1969) offers a structured framework for conceptualizing various types of active learning experiences. The premise of the model suggests that the more realistic and lifelike the stimulus, the greater the probability it has for facilitating learning. The more realistic and lifelike experiences, therefore, are located at the base of the cone (e.g. Direct, Purposeful Experiences). Each of the nine levels above the foundation of the cone is represented by a less realistic and lifelike stimulus, such that Contrived Experiences is just above the base, with Dramatic Presentation, Demonstration, Field Trips, Exhibits, Motion Pictures, Still Picture/Radio-Recordings, Visual Symbols forming progressively narrower layers. At the very top of the cone is the least realistic and lifelike experience- Verbal Experience. Applied or experiential learning, involving purposeful experiences, fits into the foundation of Dale's cone of experience. Applied learning focuses on activities that engage the learner directly in the phenomena being studied and are associated with structured reflection on the connection between the phenomena and theoretical concepts (Kendall, 1990). Students engaging in applied learning develop key competencies including effective communication, applying knowledge to new problems, and reflecting critically to improve individual and organizational performance. The implementation of applied learning has been shown to improve student performance as compared to a control group engaging in traditional learning (Acharya et al., in press). This improved performance facilitates students being able to apply or transfer concepts they learned in the classroom to different contexts or clinical cases.

Another aspect of effective management of patients with dysphagia and other complex medical conditions extends beyond swallowing-specific abilities into an exponentially expanding set of relational skills (ASHA, n.d.-b). Immediately upon entering clinical practice, new clinicians are expected to be able to demonstrate much more than the ability to meet core competencies. They must also demonstrate effective leadership qualities, be able to work well as a member of an interprofessional team, be expert lifelong learners, have the ability to problem-solve, think critically and analytically, and communicate effectively in verbal and written mediums with all stakeholders (ASHA, n.d.-b). For those students entering their clinical training experiences, they are expected to demonstrate mastery of foundational knowledge and proficiency in these additional skills such as teamwork, problem-solving, etc. all while further developing specialized competency in the area of swallowing and dysphagia. The typically didactic format of CSD's current signature pedagogy provides students with few opportunities to develop effective leadership and team member qualities, independent learning skills, problem-solving and critical thinking skills, and communication skills.

A number of specific strategies for enhancing team communication, active problem-solving, and critical thinking skills have been documented in the pedagogy literature. Team-Based Learning (TBL), in which students are strategically organized into permanent learning teams for the semester and work together to practice using course concepts to solve problems (Michaelsen \& Sweet, 2008), has been shown to facilitate improved knowledge acquisition, participation, engagement, and team performance (Haidet et al., 2014). Koles and colleagues (2010) reported on the successful implementation of TBL in a medical school. Medical students were assigned to teams and completed modules consisting of an advance assignment, including review of lecture content and readings, followed by a readiness assurance test and an application exercise. Koles et al. (2010) reported that the students included in the study achieved 5.9\% higher mean scores on 
examination questions that assessed their knowledge learned using the TBL strategy compared with questions assessing content learned via other methods.

Problem-Based Learning (PBL) is an active learning pedagogy where complex, real-world problems are used to provide context and motivate students to identify and research the concepts and principles they need to learn to address the problems (Prince, 2004). In medicine, the assigned problems often take the form of a patient problem or a community health problem. Students must take responsibility for their own learning, identifying what they need to know to better understand and manage the problem they working to solve. The learning occurs in small student groups and the educator acts as a facilitator or guide only (Barrows, 1996). PBL in SLP education is associated with improved concept map performance, suggesting improved critical thinking (Mok et al, 2014).

Critical thinking (CT) is the intellectually disciplined process of actively and skillfully conceptualizing, applying, analyzing, synthesizing, and/or evaluating information gathered from, or generated by, observation, experience, reflection, reasoning, or communication, as a guide to belief and action (Paul \& Elder, 2008). For example, in a program designed to teach critical thinking, students were required to use the "Thinking Aloud Pair Problem Solving" where a pair of students took turns verbalizing their thoughts and scaffolding their approach to the assigned work while reading or solving progressively more difficult problems (Lochhead \& Whimby, 1987).

Despite the long-standing existence of these types of active learning models, implementation of such strategies in CSD programs has been thwarted by a paucity of published evidence regarding which active learning techniques are best suited for medically complex topics like swallowing and dysphagia education. Such data could be used to guide CSD educators in designing courses that more effectively prepare CSD students to thrive in clinical practice. Therefore, the goal of this work was to examine the responses of a cohort of graduate speech-language pathology students to an active learning-oriented swallowing and dysphagia course design. Additionally, we sought to determine whether a relationship existed between student perceptions of the active learning pedagogy and academic performance or if other factors within the pedagogy were related to academic performance.

\section{Methodology}

About the Course. The Swallowing and Dysphagia course is taught in a CSD graduate program at a public Midwestern University during the fall semester of the first year of the Master of Arts in SLP program. Up to 40 students are accepted into the program each year. The course redesign was completed independent of other curricular requirements.

Course Structure. The course was structured using a flipped classroom design, which allowed educators to move away from traditional lecture by requiring students to acquire foundational knowledge before class, thereby freeing up face-to-face class time and making it possible to implement active learning techniques with students (Wallace et al., 2014). Presentation of the content was structured in a hierarchical format according to Dale's Cone of Experience (1969). It included (1) an emphasis on case studies representing the direct, purposeful experiences; (2) role playing, simulated patients, and observation representing contrived experiences, dramatic 
participation, and demonstrations; (3) videos of swallowing physiology representing motion pictures; and (4) video lectures, lecture slides, and readings representing the still pictures, visual symbols, and verbal experience.

Prior to each class meeting, students watched one to two video lectures and completed a reading with guided notetaking in order to acquire the relevant foundational knowledge. Video lectures were professionally filmed and edited at the University's instructional support center, with closed captioning provided in order to make them universally accessible. The video lectures were created using evidence-based recommendations from work completed by Guo and colleagues (2014) (i.e. invest in pre-production lesson planning to segment videos, invest in post-production editing to display the instructor's head at opportune times, videos should be 6 to 12 minutes in length) to facilitate student engagement. During class time, students first participated in a readiness assessment in the form of in-class quizzes using a classroom response system (CRS). Students then went on to complete applied learning activities in their assigned teams. These activities were intentionally designed to facilitate application of the knowledge acquired before class and to then take that application "one step further". For example, when learning about the various etiologies of swallowing impairment, students completed chart reviews of two simulated patients, one with dysphagia secondary to a stroke and one with dysphagia secondary to lingual cancer. Students were required to extract important information from the medical charts, form hypotheses about the profile of swallowing impairment for each patient, and then compare and contrast the results from the instrumental evaluations of swallowing.

To foster essential communication skills necessary for effective participation in interdisciplinary teams, students worked in teams for the duration of the course. Each team completed three PBL assignments and three CT assignments during the course (see Figure 1). The PBL assignments required students to identify and solve problems related to swallowing anatomy and physiology and apply foundational knowledge to clinical care. Specifically, one of these assignments required students to research the cranial nerves and present potential solutions related to differentiating upper and lower motor neuron impairment during an oral mechanism examination. To complete the CT assignments, students were required to appraise recent literature pertaining to swallowing rehabilitation and engage in a debate. For example, two teams researched lingual strengthening as a swallowing rehabilitation technique. One team was appraising the evidence in order to support the use of lingual strengthening. The opposing team was appraising the evidence to argue against the use of lingual strengthening. Both teams had to be mindful of their opponent's potential arguments in order to prepare rebuttal statements and were required to prepare summaries of the evidence they reviewed to share with their classmates. 


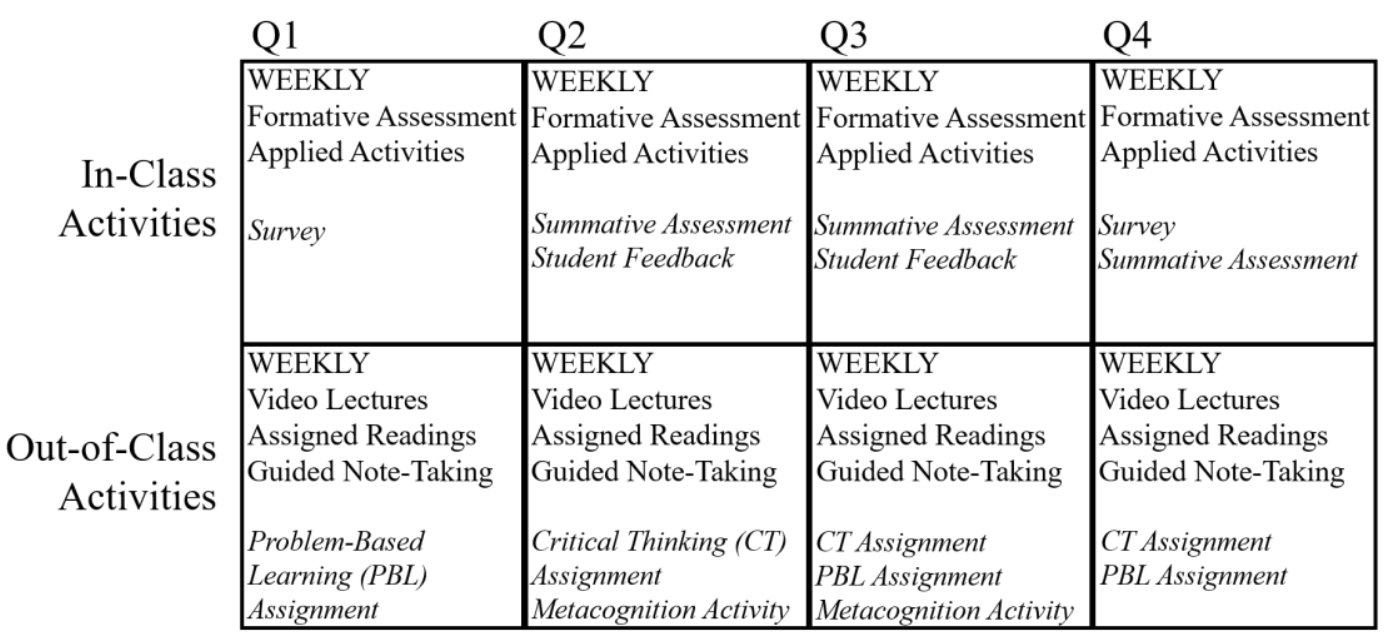

Figure 1. Structure of the 15-Week Swallowing and Dysphagia Course using Active Learning. Students completed weekly assessments and tasks both in- and out-of-class. Specific tasks assigned throughout the course are italicized.

Student Background. As shown in Table 1, the students in this sample were homogenous with respect to gender, race/ethnicity, and undergraduate GPA. All but three students in the sample had an undergraduate GPA of 3.4 or higher, and 80 percent had a GPA of 3.5 or higher, which would be expected given the competitive admission to the SLP program. Students did show variation with respect to income and first-generation status with about a third of students in each grouping.

\begin{tabular}{|l|l|l|l|}
\hline \begin{tabular}{l} 
Table 1 \\
Student demographics \\
\hline
\end{tabular} Observations & Mean & Std. Dev. \\
\hline Female & 39 & $100 \%$ & 0 \\
\hline White/Caucasian & 37 & $95 \%$ & .23 \\
\hline Low-Income & 14 & $36 \%$ & .78 \\
\hline First Generation & 11 & $28 \%$ & .46 \\
\hline Undergraduate GPA & 39 & 3.68 & .29 \\
\hline Total & 39 & & \\
\hline
\end{tabular}

Data Sources. Three main data sources were used for this study: (1) graded course work, (2) minutes of video lectures viewed, and (3) student survey data.

Graded course work consisted of in-class quizzes, three PBL projects, three team-based CT assignments, and three exams (the third was a cumulative final). The in-class quizzes were completed twice a week using a CRS and were used to identify areas of confusion/misunderstanding and increase student accountability. The PBL projects were designed to augment content delivered through the readings and video lectures. Students worked in teams to explore common issues or difficult concepts regularly encountered by clinicians. The CT assignments involved a structured analysis of current evidence and the clinical applicability of that 
evidence in the field of dysphagia management. Summative assessment was administered in the form of examinations utilizing a mix of short answer questions, open-ended essay type questions, and clinical case scenarios. Descriptive statistics regarding course activity and grades are detailed in Table 2.

\begin{tabular}{|c|c|c|c|c|c|}
\hline \multicolumn{6}{|c|}{$\begin{array}{l}\text { Table } 2 \\
\text { Graded Coursework and Minutes of Video Lectures Viewed }\end{array}$} \\
\hline & $\begin{array}{l}\text { Possible } \\
\text { Points }\end{array}$ & $\begin{array}{l}\text { Average } \\
\text { Points }\end{array}$ & Std. Dev. & Min & Max \\
\hline \multicolumn{6}{|c|}{ Foundational Content Grades } \\
\hline $\begin{array}{l}\text { Minutes of } \\
\text { Video Lectures } \\
\text { Viewed }\end{array}$ & N/A & $\begin{array}{l}236.34 \\
\text { Minutes }\end{array}$ & $\begin{array}{l}97.33 \\
\text { Minutes }\end{array}$ & $\begin{array}{l}30.79 \\
\text { Minutes }\end{array}$ & $\begin{array}{l}450.84 \\
\text { Minutes }\end{array}$ \\
\hline $\begin{array}{l}\text { Classroom } \\
\text { Response } \\
\text { (Quiz) Grade }\end{array}$ & 100 & 83.98 & 6.33 & 69 & 94 \\
\hline \multicolumn{6}{|c|}{ Applied Content Grades } \\
\hline $\begin{array}{l}\text { PBL } \\
\text { Assignment } 1\end{array}$ & 70 & 68.20 & 1.92 & 65 & 70 \\
\hline $\begin{array}{l}\text { PBL } \\
\text { Assignment } 2\end{array}$ & 70 & 68.15 & 3.25 & 60 & 70 \\
\hline $\begin{array}{l}\text { PBL } \\
\text { Assignment } 3\end{array}$ & 70 & 65.87 & 1.69 & 63 & 68.6 \\
\hline $\begin{array}{l}\text { Critical } \\
\text { Thinking } 1 \\
\end{array}$ & 70 & 62.84 & 3.17 & 59 & 70 \\
\hline $\begin{array}{l}\text { Critical } \\
\text { Thinking } 2\end{array}$ & 70 & 61.23 & 2.85 & 57 & 66 \\
\hline $\begin{array}{l}\text { Critical } \\
\text { Thinking } 3 \\
\end{array}$ & 70 & 66.30 & 2.72 & 61 & 70 \\
\hline \multicolumn{6}{|c|}{ Foundational and Applied Content Grades } \\
\hline Exam 1 & 107 & 90.30 & 10.17 & 58 & 107 \\
\hline Exam 2 & 103 & 92.10 & 8.31 & 72 & 103 \\
\hline Exam 3 (Final) & 103 & 83.92 & 8.94 & 68 & 103 \\
\hline Course Grade & 100 & 90.30 & 3.48 & 80 & 97 \\
\hline
\end{tabular}

The course management system (CMS) allowed for tracking the video lecture viewing behaviors for each student, including the amount of time and number of times video lectures were viewed. Students had access to 26 videos which totaled 230 minutes of content. On average, students watched each video once, but this varied a great deal by student with one student only watching 30 minutes of content and another student viewing seven and a half hours. 
The student survey contained Likert-style questions that asked students to reflect on their active learning experiences. This instrument was a modified Social Context and Active Learning (SCALE) survey, adapted from the University of Minnesota team (Walker \& Baepler, n.d.). To better understand potential patterns in student responses to the modified SCALE survey, an exploratory factor analysis of the student survey data identified five main factors.

Once the survey factors were identified, the next step was to understand the relationship between student survey responses and student classroom performance. To do this, each of the five identified factors was correlated against the quizzes, the exams, and the final course grade. Given the exams make up a large part of the final course grade, these correlations were omitted.

To allow for a deeper exploration the relationship between the active learning factors and the course structure, identical correlations were also completed between the course assignments with the five identified active learning factors from the student survey. The course assignments included three team critical thinking assignments, three team PBL assignments, and watching video lectures out of class. The critical thinking and PBL assignments were measured with respect to the grade the student received while the video lectures were measured in terms of minutes of video viewed by each student.

\section{Results}

Student Responses to the Modified SCALE Survey. Five main factors (outlined in Table 3) were identified following the exploratory factor analysis of the student responses to the SCALE survey. Factor 1 measures a concept labeled The Environment, and the survey questions asked students about the classroom atmosphere such as "increases excitement", "engages me in the learning process", or "develops professional skills". Factor 2 was labeled the Active Learning Interactions, which surveyed students on "explaining concepts to others", "learning from people sitting near me", and "working well with others". Factor 3 was labeled Relationships and the survey questions asked students about their relationships with other students and the instructor in the course such as "my instructor wants me to do well" and "I am acquainted with the students sitting near me." Factor 4 focused exclusively on the Instructor (e.g. "My instructor makes class enjoyable") and is therefore labeled as such. Finally, Factor 5, In-Class Activities, focused on the in-class learning experiences with the instructor, other students, and activities such as "an in-class activity required students to explain a concept to other students." Each factor was determined to have acceptable $(0.7 \leq \alpha<0.8)$, good $(0.8 \leq \alpha<0.9)$, or excellent $(0.9 \leq \alpha)$ reliability using Cronbach's alpha (George \& Mallery, 2003).

Relationships between Student Performance and Active Learning Factors. Significant correlations, all reported in Table 4 and Table 5 below, were identified between elements of student performance and the active learning factors. 
Teaching and Learning in Communication Sciences \& Disorders, Vol. 4 [2020], Iss. 2, Art. 4

\begin{tabular}{|l|l|l|}
\hline \multicolumn{2}{|l|}{ Table 3 } \\
\multicolumn{3}{|l|}{ Student Survey Factors } \\
\hline & $\begin{array}{l}\text { Cronbach's } \\
\text { alpha }\end{array}$ & Concept Measured \\
\hline Factor 1 & 0.98 & The Environment \\
\hline Factor 2 & 0.93 & Active Learning Interactions \\
\hline Factor 3 & 0.85 & Relationships \\
\hline Factor 4 & 0.89 & Instructor \\
\hline Factor 5 & 0.78 & In-class Activities \\
\hline
\end{tabular}


Table 4

Correlations between exams and course grades with active learning factors

\begin{tabular}{|c|c|c|c|c|c|c|c|c|}
\hline & $\begin{array}{l}\text { The } \\
\text { Environment }\end{array}$ & $\begin{array}{l}\text { Active } \\
\text { Learning } \\
\text { Interactions }\end{array}$ & Relationships & Instructor & $\begin{array}{l}\text { In-class } \\
\text { Activities }\end{array}$ & Exam 1 & Exam 2 & Exam 3 \\
\hline Exam 1 & $\begin{array}{l}0.076 \\
0.6549\end{array}$ & $\begin{array}{l}0.3562 * \\
0.0305\end{array}$ & $\begin{array}{l}0.1015 \\
0.5499\end{array}$ & $\begin{array}{l}0.0151 \\
0.9291\end{array}$ & $\begin{array}{l}-0.1752 \\
0.2997\end{array}$ & & & \\
\hline Exam 2 & $\begin{array}{l}0.1232 \\
0.4676\end{array}$ & $\begin{array}{l}0.4380^{*} \\
0.0067\end{array}$ & $\begin{array}{l}0.1467 \\
0.3864\end{array}$ & $\begin{array}{l}-0.0351 \\
0.8368\end{array}$ & $\begin{array}{l}-0.009 \\
0.9579\end{array}$ & $\begin{array}{l}0.5713^{*} \\
0.0001\end{array}$ & & \\
\hline Exam 3 & $\begin{array}{l}0.1914 \\
0.2564\end{array}$ & $\begin{array}{l}0.3800 * \\
0.0203\end{array}$ & $\begin{array}{l}0.1167 \\
0.4916\end{array}$ & $\begin{array}{l}-0.0448 \\
0.7923\end{array}$ & $\begin{array}{l}-0.0899 \\
0.5967\end{array}$ & $\begin{array}{l}0.4646^{*} \\
0.0029\end{array}$ & $\begin{array}{l}0.6012 * \\
0.0001\end{array}$ & \\
\hline Quiz Grade & $\begin{array}{l}0.1538 \\
0.3633\end{array}$ & $\begin{array}{l}0.3863 * \\
0.0182\end{array}$ & $\begin{array}{l}0.093 \\
0.5842\end{array}$ & $\begin{array}{l}-0.0683 \\
0.6881\end{array}$ & $\begin{array}{l}0.0076 \\
0.9645\end{array}$ & $\begin{array}{l}0.0656 \\
0.6917\end{array}$ & $\begin{array}{l}0.1314 \\
0.4251\end{array}$ & $\begin{array}{l}0.1876 \\
0.2527\end{array}$ \\
\hline Course Grade & $\begin{array}{l}0.3294^{*} \\
0.0465\end{array}$ & $\begin{array}{l}0.5720^{*} \\
0.0002\end{array}$ & $\begin{array}{l}0.092 \\
0.5881\end{array}$ & $\begin{array}{l}-0.0191 \\
0.9105\end{array}$ & $\begin{array}{l}-0.1684 \\
0.3191\end{array}$ & $\begin{array}{l}\text { Omitted } \\
* *\end{array}$ & $\begin{array}{l}\text { Omitted } \\
* *\end{array}$ & $\begin{array}{l}\text { Omitted } \\
* *\end{array}$ \\
\hline
\end{tabular}

Notes: $*=$ Significant at $\mathrm{p}<0.05 ; * *=$ Was omitted since exam makes up part of course grade. 
Table 5

Correlations between active learning factors and course assignments

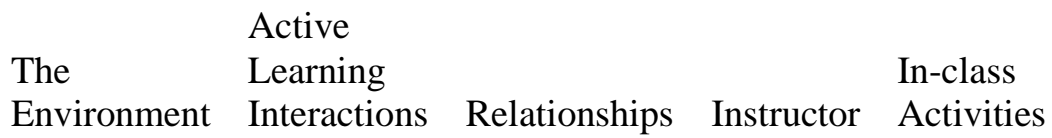

$\begin{array}{llllll}\text { PBL Assignment 1 } & 0.3498^{*} & -0.0694 & -0.1485 & -0.099 & -0.0721 \\ & 0.0338 & 0.6832 & 0.3805 & 0.5601 & 0.6714 \\ & & & & & \\ \text { PBL Assignment 2 } & 0.3042+ & 0.1052 & -0.068 & -0.0248 & -0.066 \\ & 0.0672 & 0.5355 & 0.6891 & 0.8843 & 0.698 \\ \text { PBL Assignment 3 } & 0.2433 & 0.1265 & -0.1 & -0.0477 & -0.3203 \\ & 0.1467 & 0.4556 & 0.556 & 0.7792 & 0.0532 \\ & & & & & \\ \text { Critical Thinking 1 } & 0.5189^{*} & 0.034 & 0.0002 & -0.0658 & -0.0244 \\ & 0.001 & 0.8419 & 0.9992 & 0.6989 & 0.8859 \\ & & & & & \\ \text { Critical Thinking 2 } & 0.3456^{*} & 0.1725 & 0.0415 & 0.0796 & -0.4965^{*} \\ & 0.0361 & 0.3072 & 0.8075 & 0.6394 & 0.0018 \\ \text { Critical Thinking 3 } & 0.32 & 0.2961+ & -0.1656 & -0.0355 & -0.2465 \\ & 0.0535 & 0.0752 & 0.3274 & 0.8349 & 0.1413 \\ & & & & & \\ \text { Video Minutes } & -0.0123 & -0.079 & -0.2519 & 0.1844 & -0.0265 \\ & 0.9424 & 0.6419 & 0.1326 & 0.2746 & 0.8761\end{array}$

Notes: $*=$ Significant at the $\mathrm{p}<0.05 ;+=$ Significant at the $\mathrm{p}<0.10$

\section{Discussion}

This analysis identified two important relationships as it relates to the change to an active learning format. First, the relationship between exam performance and Active Learning Interactions with peers, and second, the relationship between course assignments and The Environment of the classroom. Both of these findings have implications for active learning pedagogy as it relates to student learning.

The Active Learning Interactions factor included questions focused on being able to engage with peers in an academic manner (e.g. "the students sitting near me rely on each other for help learning the class material") and also being able to teach peers (e.g. "the people sitting around me learned something from me in class"). This seems to indicate that students who had mastered the content to a level where they could teach and support their peers performed better on traditional 
examinations and quizzes. The activities in class, and more broadly, the change to an active learning format, more frequently put students in situations where they were required to take ownership of learning the material as part of a team and teaching it back to peers. These findings are encouraging given that the revised structure of the course placed a strong emphasis on teambased learning (through PBL assignments) and students were heavily reliant on peers for teaching each other the material. This ability to work in teams and take ownership for learning seems to be reflected in quiz and exam performance.

Second, students that had a more positive perception of The Environment were also more likely to have a higher overall course grade. Here, it is not the quiz or exam grades driving the relationship, but rather the course assignments as evidenced by the significant correlations between four of the six course assignments and the environment factor. This seems intuitive in that students would enjoy an environment where they are working with peers compared to listening to a lecture. It is exciting, given the purpose of this work, to see that students reported experiencing a positive classroom environment as a result of the changes to active learning pedagogy and that these feelings carried over to better performance on course assignments.

At first glance, the lack of impact of the Instructor seems disappointing but this might be due to the fact that the students have such a great responsibility for learning in this revised structure that the instructor is more of a facilitator then a deliverer of knowledge. Interpersonal Relationships also did not show any type of correlation which may be an indication that the academic interactions and ability to work as a team are more impactful with respect to grades than students having a good interpersonal relationship with their classmates.

No relationships were identified between student performance and the amount of time spent watching video lectures. This may have been due to the large variation in viewing time between students (30 minutes to seven and a half hours).

\section{Limitations}

Given this was the initial phase of this work, the major limitation of this study is sample size, as this data comes from just one cohort of students in one course. The analysis undertaken allows for results that are strictly correlational and should not in any way be interpreted to be a causal link between learning, student behaviors, and instructional pedagogy. Due to the homogeneity of the population in this course, it is also not possible to make inferences towards the larger student population in practitioner courses or other contexts. With respect to the impact of this work on student clinician performance in the field, interviews and feedback from clinical supervisors will be needed to validate any findings.

\section{Future Work}

There are two main areas of future work for this project. The first is to collect additional supporting data and the second is to further test the impact of course changes on student clinician performance in clinical practice. This was the first data collection of a new study so one priority will be to test the robustness of our findings by repeating our work across multiple cohorts of students. Should 
the initial findings hold, expanding testing across different instructors and institutions will inform whether these changes are scalable across different contexts.

Given the goal of this project was to improve student clinician performance and care of clients, getting additional interview and focus group data from clinical supervisors will be critical to measuring to what extent student performance in the classroom translates into improved provision of services in clinical practice. Some preliminary data related to this goal has been collected and more will become available as more cohorts of students move through the program. One year (four semesters) after the students completed the active learning swallowing and dysphagia course, they participated in the final clinical internship, which is comprised of 36+ hours per week for a minimum of 14 weeks with an off-campus clinical supervisor. These internships are completed in a variety of different environments with different client populations. Twenty-six students engaged in swallowing and dysphagia-related clinical activities during their final clinical internship. Two clinical supervisors, each supervising one student with a caseload primarily composed of clients requiring dysphagia management, agreed to participate in a semi-structured interview pertaining to the performance of the student clinicians they were supervising. The transcripts of these interviews were analyzed for evidence that students may be translating skills, developed during the active learning course, into clinical practice. Given the small number of clinical supervisors who participated, a qualitative analysis of the interview transcripts could not be completed; however, initial review of the transcripts suggests that the students demonstrated strengths in the areas of critical thinking and problem solving. Initial reports from two clinical supervisors suggest that these findings also transferred over to performance in clinical practice. This was evidenced by comments such as "she really thinks through [all the outcomes] before she actually does it. And to me, that's what a good clinician does" and "she gave that to the [physical therapist] and [occupational therapist] and said 'this helps the patient tell you what he wants or needs.' That, to me, speaks volumes to ensuring that we're not just focused on 'what are our needs in speech and language?'; we are focused on the patient as a whole and making sure that we're [working] with other members of [the medical team]". This is also in line with previous research suggesting that students truly know content when they are able to teach it to their peers. Given the clinical nature of the course, this also advances the initial goal of this work which is to improve delivery of care to patients when these students are practicing in the field.

\section{Conclusion}

This project aimed to improve metacognitive skills, preparedness for clinical practice, collaboration skills, problem-solving, critical thinking, and the written and verbal communication skills of future SLPs using an active learning model of instruction. In this study, an active learning approach with a focus on applied learning in an SLP Swallowing and Dysphagia course was implemented and the outcomes related to student perceptions and performance were examined.

From our student survey questionnaire, five reliable factors were identified. With respect to exam scores and course grades, students' Active Learning Interactions with peers showed the strongest association. This is likely due to the team based structure of the course where students assume greater responsibility for their learning and the learning of their peers. With respect to the course assignments, The Environment showed the strongest association suggesting that some students were able to leverage the different classroom structure more advantageously than others. Two 
interviews with clinical supervisors were conducted at the end of the following term, once students had completed their final clinical internship. While only a limited sample, the initial interviews suggest that the skills gained in this revised course structure translated into clinical practice when students engaged in clinical practice.

\section{Disclosures}

IRB approval was applied for but not needed as the board deemed this work was not research.

Rebecca Affoo was previously employed by Central Michigan University and is now employed by Dalhousie University. She has no other relevant financial relationships to disclose. Rebecca Affoo has previously served as a reviewer for TLCSD and has no other relevant non-financial relationships to disclose. This research was supported in part by an American Speech-LanguageHearing Association's Advancing Academic-Research Career (AARC) Award (RHA).

Justin L. Bruner is employed by Michigan State University and has no other relevant financial relationships to disclose. He has no relevant non-financial relationships to disclose.

Angela M. Dietsch is employed by the University of Nebraska-Lincoln and has no other relevant financial relationships to disclose. Angela Dietsch has previously served as a reviewer for TLCSD and has no other relevant non-financial relationships to disclose.

Ciara E. Nellenbach has no relevant financial or nonfinancial relationships to disclose.

Theresa M. Jones is employed by Central Michigan University and has no other relevant financial relationships to disclose. She has no relevant non-financial relationships to disclose.

Mark E. Lehman is employed by Central Michigan University and has no other relevant financial relationships to disclose. He has no relevant nonfinancial relationships to disclose.

\section{References}

American Speech-Language-Hearing Association. (n.d.-a). 2020 Standards and implementation procedures for the certificate of clinical competence in speech-language pathology. https://www.asha.org/Certification/2020-SLP-Certification-Standards/

American Speech-Language-Hearing Association. (n.d.-b) Responding to the changing needs of speech-language pathology and audiology students in the 21st century: A briefing paper for academicians, practitioners, employers, and students. https://www.asha.org/academic/reports/changing/

Acharya, H., Rakesh, R., Hussein, A., Bagga, J., \& Petit, T. (in press). The effectiveness of applied learning: An empirical evaluation using role playing in the classroom. Journal of Research in Innovative Teaching \& Learning. https://doi.org/10.1108/JRIT-06-2018-0013 
Ball, K. A., \& Riquelme, L. F. (2016). The graduate dysphagia course: Opening the door to new frontiers. Perspectives of the ASHA Special Interest Groups, 1(3), 104-112. https://doi.org/10.1044/persp1.SIG13.104

Barrows, H. S. (1996). Problem-based learning medicine and beyond: A brief overview. In R. J. Menges \& M. D. Svincki B (Eds.), Bringing problem-based learning to higher education theory and practice (pp. 3-12). Jossey-Bass Publishers.

Bonwell, C. C., \& Eison, J. A. (1991). Active learning: Creating excitement in the classroom. School of Education and Human Development, George Washington University.

Brackenbury, T., Folkins, J. W., \& Ginsberg, S. M. (2014). Examining education challenges in communication sciences and disorders from the perspectives of signature pedagogy and reflective practice. Contemporary Issues in Communication Science and Disorder, 41, 70-82. https://doi.org/1092-5171/14/4101-0070

Dale, E. (1969). Audio-visual methods in teaching ( $3^{\text {rd }}$ ed.). Holt, Rinehart \& Winston.

Deslauriers, L., Schelew, E., \& Wieman, C. (2011). Improved learning in a large-enrollment physics class. Science, 332(6031), 862-864. https://10.1126/science.1201783

Di Vesta, F. \& Smith, D. (1979). The pausing principle: Increasing the efficiency of memory for ongoing events. Contemporary Educational Psychology, 4(3), 288-296. https://doi.org/10.1016/0361-476X(79)90048-1

Freeman, S., Eddy, S. L., McDonough, M., Smith, M. K., Okoroafor, N., Jordt, H., \& Wenderoth, M. P. (2014). Active learning increases student performance in science, engineering, and mathematics. Proceedings of the National Academy of Sciences of the United States of America, 111(23), 8410-8415. https://doi.org/10.1073/pnas.1319030111

George, D., \& Mallery, P. (2003). SPSS for Windows step by step: A simple guide and reference. 11.0 update (4th ed.). Allyn \& Bacon.

Ginsberg, S. M. (2010). Getting to the scholarship of teaching and learning: Professional development in university faculty. The ASHA Leader, 15, 14-17. https://doi.org/10.1044/leader.FTR2.15102010.14

Guo, P., Kim, J., \& Rubin, R. (2014). How video production affects student engagement: An empirical study of MOOC videos. 41-50. https://doi.org/0.1145/2556325.2566239.

Haidet, P., Kubitz, K., \& McCormack, W. (2014). Analysis of the team-based learning literature: TBL comes of age. Journal on Excellence in College Teaching, 25(3-4), 303-333.

Hake, R. R. (1998). Interactive-engagement vs. traditional methods: A six-thousand-student survey of mechanics test data for introductory physics courses. American Journal of Physics, 66(1), 64-74. https://doi.org/10.1119/1.18809

Kendall, J. C. (1990). Combining service and learning. A resource book for community and public service (Volume II). National Society for Internships and Experiential Education.

Koles, P., Stolfi, A., Borges, N., Nelson, S., \& Parmelee, D. (2010). The impact of team-based 
learning on medical students' academic performance. Academic Medicine, 85(11), 173945. https://doi.org/10.1097/ACM.0b013e3181f52bed

Laws, P., Sokoloff, D., \& Thornton, R. (1999). Promoting active learning using the results of physics education research. UniServe Science News, 13, 14-19.

Lochhead, J. \& Whimby, A. (1987). Teaching analytical reasoning through think-aloud pair problem solving. New Directions for Teaching and Learning, 1987(30), 73-92. https://doi.org/10.1002/t1.37219873007

Michaelsen, L. \& Sweet, M. (2008). The essential elements of team-based learning. New Directions for Teaching \& Learning, 2008(116), 7-27. https://doi.org/10.1002/t1.330

Mok, C. K., Whitehill, T. L., \& Dodd, B. J. (2014). Concept map analysis in the assessment of speech-language pathology students' learning in a problem-based learning curriculum: A longitudinal study. Clinical Linguistics and Phonetics, 28(1-2), 83-101. https://doi.org/10.3109/02699206.2013.807880

Paul, R. \& Elder, L. (2008). The miniature guide to critical thinking: Concepts and tools. TheFoundation for Critical Thinking.

Prince, M. (2004). Does active learning work? A review of the research. Journal of Engineering Education, 93(3), 223-231. https://doi.org/10.1002/j.2168-9830.2004.tb00809.x

Redish, E., Saul, J., \& Steinberg, R. (1997). On the effectiveness of active-engagement microcomputer-based laboratories. American Journal of Physics, 65(1), 45-54. https://doi.org/10.1119/1.18498

Ruhl, K., Hughes, C., \& Schloss, P. (1987). Using the pause procedure to enhance lecture recall. Teacher Education and Special Education, 10, 14-18. https://doi.org/10.1177/088840648701000103

Walker, J. D., \& Baepler, P. (n.d.) Learning spaces research: Survey instruments. University of Minnesota. research/home/instruments

Wallace, M. L., Walker, J. D., \& Braseby, A. M. (2014). "Now, What Happens During Class?”: Using team-based learning to optimize the role of expertise within the flipped classroom. Journal on Excellence in College Teaching, 25, 253-273. 